peritoneal surface of the diaphragm. The other group is of considerable interest as it is possible to construct from examination of these cases a picture of the lung changes in compression asphyxia.

In cases of compression asphyxia where the victim has been buried under debris death has presumably been slow, with attempts at respiration. In such conditions rib markings have been observed; a dark purple line of the size and direction of the rib is seen, with emphysematous bullae visible at the margin of the dark rib marking. In addition these cases showed some scattered haemorrhages into the lung, with subpleural Tardieu's spots. There are localized areas of collapse. Microscopically there is disruption of the alveolar walls where the rib marking has been sectioned. There is fresh blood in the alveoli, and clotting may have begun in some areas. Elsewhere there is general congestion of all the capillaries in the alveolar walls and a considerable number of thromboses in smaller arterioles and veins. Oedema is present in many areas.

So far it has been possible to correlate these wartime injuries with peacetime parallels. Another group is without parallel. This includes cases in which death may be found to have occurred without or with only trifling external injury, but in which intrapulmonary haemorrhage has been a post-mortem feature common to them all. These cases have all been found near to the site of explosion of a bomb. In view of this fact the condition may well be called "haemorrhagic pulmonary concussion"; it may or may not be due to blast from the high explosive. It may prove to be of interest in the elucidation of the actual causes of this concussion that where these pulmonary lesions have been found and there have been external markings of small splinters, etc., the superficial lesions have all been on the anterior surface of the body.

Subpleural haemorrhages are not conspicuous and haemorrhagic rib markings are not present in the pleura. The haemorrhagic areas are scattered through, and often deep in, the substance of the lung, most of ten posteriorly and towards the base. The degree of haemorrhage varies considerably, but both lungs are affected to the same degree.

Comparing the histology of these cases with that found in compression asphyxia, it is seen that oedema is not a feature. Thromboses are not present. The haemorrhage in those patients found dead is fresh, and clotting has not occurred. There is widespread and intense capillary congestion in the lungs. There is haemorrhage into the walls of the small bronchioles, but absence of bleeding into the walls of the bronchi. There is some over-distension of air vesicles and respiratory bronchioles in some cases. but there is no anatomical relation of these to the ribs.

At the present time it is not known how many of the air-raid casualties dying with gross fatal injury, apparent externally, show pulmonary lesions such as these, but it is beyond question that these appearances are a definite morbid entity distinct from conditions hitherto familiar, and are distinguishable on careful analysis from lesions due to compression asphyxia or to pulmonary haemorrhage due to impact of solids against the thoracic wall.

\section{Conclusion}

The main points of difference may be summarized as follows :

In compression asphyxia the lesions may be symmetrical on both sides, but not necessarily so. The haemorrhages are usually subpleural and in the lines of the ribs. Emphysema may outline these rib markings. There is

generalized congestion of the lungs and some oedema. Tardieu's spots are nearly always found.

In haemorrhage due to impact of a solid the haemorrhage is in relation to the point of maximum impact and may be unilateral. The lung tissue is contused, torn. and filled with blood at or around this point.

In haemorrhagic concussion the lesions are always bilateral and roughly symmetrical. There is general songestion of the lungs. Pleural haemorrhages are present only as an extension from deeper areas.

\title{
FAMILIAL PERIODIC PARALYSIS
}

BY

\section{J. MacDONALD HOLMES, M.D., M.R.C.P.}

Physician, Staffordshire General Infirmary; Major, R.A.M.C., Medical Specialist

The following brief study of two cases of familial periodic paralysis is recorded because of the rarity of the disease. The patients were brothers recently enlisted in different units, and their disability was first noticed after exercise. The chemical investigations were limited by military conditions and are by no means complete.

Familial periodic paralysis is characterized by sudden attacks of flaccid paralysis in one or more muscle groups. generally in the limbs. The paralysis is usually symmetrical. The trunk muscles are seldom involved, and much more rarely the muscles supplied by the cranial nerves. There is a complete loss or diminution of the tendon reflexes in the affected muscles, and usually the electrical excitability to both faradic and galvanic currents is lost or diminished. The duration of the attacks varics from a few hours to three or four days. They vary greatly in frequency, occurfing every few days or at intervals of several months. Sphincter control is rarely affected, and very infrequently death occurs from respiratory paralysis. Biemond and Daniels (1934) have described a muscular atrophy developing in later life in the muscles most affected by the paralysis, but this complication is rare. There is usually little difficulty in diagnosing the cases with a familial incidence, but occasional sporadic cases occur which may be regarded as hysteria.

Until recently the factors causing the disease, apart from the inherited predisposition, have remained obscure. The first real advance in the understanding of the condition was made by Aitken, Allott, Castleden, and Walker (1937). These observers found that during the attacks of paralysis there was an abnormally low serum-potassium level and that the paralysis could be cut short by the administration of potassium chloride by mouth. They also found that paralysis could be induced by giving large amounts of glucose by mouth, either alone or together with insulin injections. These observations were confirmed in two further cases by Allott and McArdle (1938).

The fall in the serum-potassium content had been observed by Biemond and Daniels (1934), but they did not realize its significance. Treatment with potassium salts was mentioned as early as 1902 by Mitchell, Flexner, and Edsell, also by Holtzapple in 1904, and by Herrington in 1937. Holtzapple used potassium bromide, and ascribed the benefit to the bromide rather than to the potassium. Herrington used potassium citrate in 5 gramme doses with success in two cases. 
In the first case here recorded the attacks of paralysis could be induced by giving large doses of glucose. During an attack the serum-potassium level was found to be low. Potassium salts by mouth caused a rapid disappearance of the paralysis, with a simultaneous rise in the serum-potassium level. Attempts to induce paralysis in the second case were unsuccessful, and apart from the history there is no definite evidence that this patient suffered from the disease.

\section{Case I}

Gunner A, aged 26, was admitted to hospital with flaccid paralysis of the arms and legs following a strenuous day of physical training. When seen the paralysis had almost recovered, but he stated that he had had similar attacks since the age of 15 , occurring at varying intervals, usually of a few weeks. All four limbs are paralysed during the attacks and often the muscles of the back as well. Speech is not affected, but occasionally swallowing is difficult. Severe exercise will bring on an attack the following day. He also states that a few glasses of beer will precipitate an attack. The paralysis lasts for three or four days as a rule, and some residual stiffness and aching persists in the affected muscles for about a week afterwards. He has warning of the onset in the form of a "tight feeling" in the arms, legs, and back. He feels very thirsty during an attack, but not hungry. No palpitation or dyspnoea has occurred, nor has there been any loss of sphincter control.

His mother is siightly affected. but with advancing years her attacks have practically disappeared. One brother (Case II) is affected. The accompanying family tree shows that seven members of the family are known to have been affected; these are shown in black.

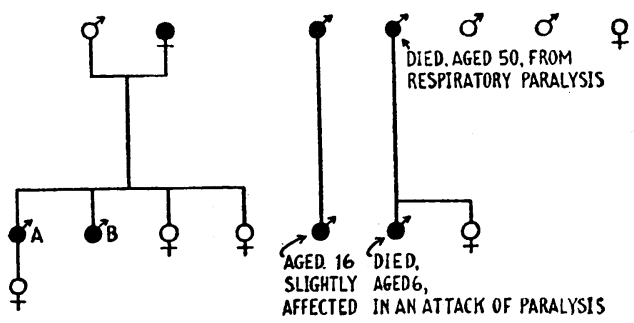

A complete physical examination revealed no abnormality during a period of freedom from paralysis. There was no muscular wasting, and all the tendon jerks were brisk. The electrical reactions of all the muscles were normal. The administration of glucose in 50-gramme doses with 25 units of insulin three times a day did not induce paralysis, nor did the injection of adrenaline in 5 -minim doses half-hourly for twelve hours.

On April 2, 1940, 200 grammes of glucose was given at 10 a.m. An attack of paralysis began about 1 a.m. the following day. Weakness was maximal in the upper arms, back, and legs. The forearms were only slightly weak and toe-wriggling movements could be performed. All the tendon jerks were absent with the exception of those of both triceps and the knees, which could just be elicited. The pulse rate remained unchanged. the blood pressure was $130 / 75$. There were no sensory changes apart from tenderness and aching of the muscles involved. Twelve grammes of potassium chloride was given by mouth at 10 a.m. on April 3. The paralysis had completely disappeared by noon, but some stiffness and aching remained. The tendon jerks all reappeared as the paralysis was passing off. The potassium chloride produced severe nausea, so it was decided to use potassium citrate on future occasions. A fractional test meal showed a normal secretion of free hydrochloric acid. and a glucosetolerance curve was normal.

On April 17 another attack of paralysis was induced by giving a further 200 grammes of glucose at 10.30 a.m. As before, the onset of paralysis was about 1 a.m. the following dav. The serum-potassium level at 10 a.m. on the $17 \mathrm{th}$ was $18.9 \mathrm{mg}$. per $100 \mathrm{c.cm}$. On this occasion all the tendon jerks disappeared, and the electrical reactions were present but sluggish in the affected muscles. Serum-potassium and blood-sugar cetimations were made during the period of recovery and the following figures were obtained:

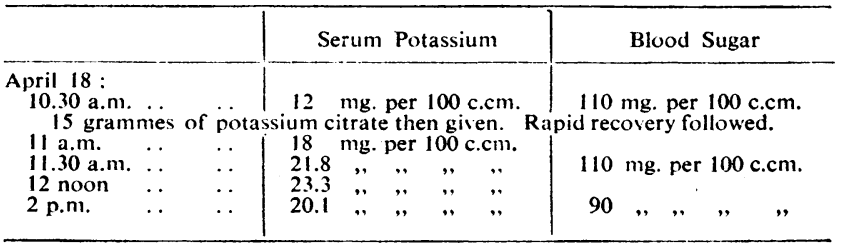

The tendon jerks were present at 11 a.m. and had fully returned at 2 p.m.

The urinary excretion of potassium was estimated during the two days covering the period of paralysis and the following figures were obtained:

\begin{tabular}{|c|c|c|c|}
\hline April 17 & & & $\begin{array}{l}\text { Urinary Excretion } \\
\text { of Potassium }\end{array}$ \\
\hline Between & $10 \mathrm{a} . \mathrm{m}$. and midnight & . & .. $0.19 \mathrm{gm}$. \\
\hline \multicolumn{4}{|l|}{ April 18: } \\
\hline Between & midnight and 10.30 a.m. & $\cdots$ & . $0.172 \mathrm{gm}$. \\
\hline , & 10.30 a.m. and 2.30 p.m. & . & . $0.126 \mathrm{gm}$. \\
\hline , & 2.30 p.m. and 9.30 p.m. . & $\cdots$ & . $\quad 2.964 \mathrm{gm}$. \\
\hline , & $9.30 \mathrm{p} . \mathrm{m}$. and $5.30 \mathrm{a} . \mathrm{m}$. & . & $\ldots \quad 1.5 \mathrm{gm}$ \\
\hline
\end{tabular}

\section{Case II}

Private B. aged 23, the younger brother of Gunner A, stated that his. first attack of paralysis occurred at the age of 17 . The attacks are infrequent and by no means as severe as those of his brother. They are brought on by severe exercise, and he has had one attack since he joined the Army-following a long route march. As in Case $I$, the paralysis usually occurs when he is in bed at night, and when severe it lasts for two or three days. He has no premonitory signs or symptoms.

On April 26 physical examination revealed no abnormality. All attempts to induce an attack of paralysis failed. Glucose alone, glucose with insulin, and adrenaline did not cause the slightest muscular weakness. The following serum-potassium and blood-sugar estimations were made

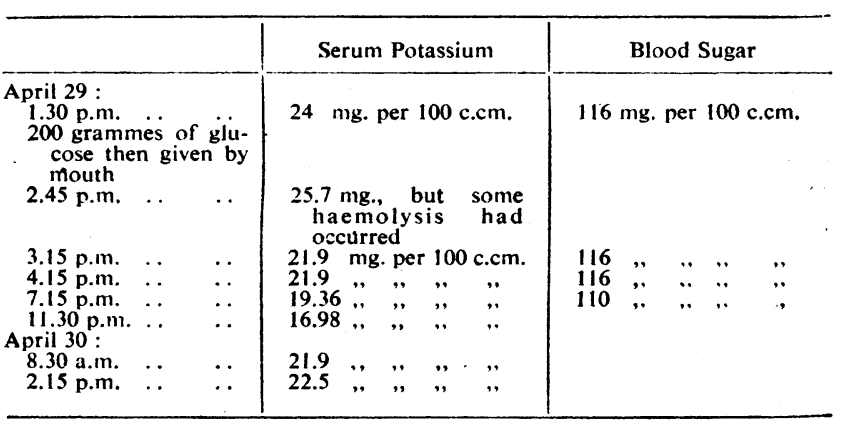

The investigation of this case was not pursued further.

\section{Commentary}

The low level of the serum-potassium content during the period of paralysis in Case $I$ and the rapid recovery following the giving of potassium. salts by mouth correspond with the observations of Aitken, Allott, Castleden, and Walker (1937) and Allott and McArdle (1938). The estimations of the urinary excretion of potassium, although incomplete, suggest that there was a retention of potassium in the body during the period of paralysis and its onset.

Ferrebee, Atchley, and Loeb (1938), and Pudenz, McIntosh, and McEachern (1938) showed that potassium is retained in the body during the attacks of paralysis. Gammon, Austin, Blithe, and Reid (1939) have shown that in the late hours of the night potassium excretion 
was unusually low and that water diuresis rapidly washed out potassium from their patient, with a fall in the serum potassium and development of paralysis. Pudenz, McIntosh, and McEachern found that if the venous return of one arm was obstructed the injection of potassium chloride into an artery of the limb did not produce a return of function. If, however, the circulation of the limb was completely obstructed injection of potassium chloride into the other arm produced a return of function equally quickly in both limbs. They therefore suggested that a central factor may be at work. It has been shown that intravenous injection of choline esters such as doryl and mecholyl will cut short an attack of paralysis without the administration of potassium, and that after these drugs the serum potassium rises.

An interesting similarity to the action of potassium in familial periodic paralysis occurs in myasthenia gravis. Laurent and Walther (1935) first showed that potassium salts were a valuable adjuvant to prostigmin in the latter condition and might even replace it in some cases. Cumings $(1939,1940)$ has shown that there is a retention of potassium in the muscle substance during the periods of weakness in myasthenia gravis.

Our knowledge of the mechanisms involved in the causation of attacks of familial periodic paralysis is still very incomplete, but the available evidence suggests that an abnormal metabolic process in the muscle fibres is responsible, and not any central factor in the nervous system. Allott and McArdle (1938) found that the phosphorus metabolism runs parallel with that of potassium and suggest that a quantitative or qualitative disturbance of hexose phosphate metabolism is involved. The similarity to myasthenia gravis suggests that there may be common factors in the two conditions.

The serum potassium was estimated colorimetrically by a cobaltinitrite precipitation method. The same method was applied to the urine after making it alkaline and removing the ammonia by adding formaldehyde.

REFERENCES

Aitken, R. S., Allott, E. N., Castleden, L. 1. M., and Walker, M. (1937). Clin. Sci., 3, 47

Allott, E. N., and McArdle, B. (1938). Jbid.. 3, 229

Bicmond, A., and Daniels, P. (1934). Brain, 57, 91.

Cumings, J. N. (1939). Ibid., 62, 153.

- (1941)). J. Neurol. Psychiat., 3, 115.

Ferrebee, J. W., Atchley, D. W., and Locb, R. F. (193\$). J. clin. Invest., 17,504 .

Gammon, G. D.. Austin, J. H., Blithe, M. D., and Reid. C. G. (1939). Amer. J. med. Sci. 197, 326

Herrington, M. S. (1937), J. Amer. med. Ass., 108, 1339

Holtzapple, G. E. (1904). Ibid., 45, 1224

Laurent, L. P. E., and Walther, W'. W. (1935). Lancet, 1, 1434.

Mitchell, J. K., Flexner, S., and Edsell. D. L. (1902). Brain, 25. 109

Pudenz, R. H., McIntosh, J. F., and McEachern. D. (1938). J. Amer. med. Ass., 111, 2253.

Dr. John E. Gordon, Professor of Preventive Medicine and Epidemiology at Harvard University, has made a brief statement of his plans for setting up in this country the American Red Cross Harvard Hospital for Infectious Diseases. The plan envisages three distinct activities: (1) the hospital proper for the care of patients; (2) research laboratories for the study of clinical problems and epidemiology ; (3) field study in epidemiology and infections diseases. Dr. Paul V. Beeson, formerly of the Rockefeller Institute Hospital in New York, will be in charge of the hospital; Dr. MacNair Scott, Research Professor of Pediatrics at the University of Pennsylvania, will supervise the laboratory work; Dr. John Mote, Assistant in Epidemiology at Harvard Medical School, will undertake epidemiological investigations: and field studies will be under the direction of Dr. Dean Fleming of the Harvard School of Public Health.

\section{SOME PUBLIC HEALTH CONSIDERATIONS CONSEQUENT UPON A LARGE-SCALE AIR RAID}

BY

\author{
ARTHUR MASSEY, M.D., D.P.H. \\ Medical Officer of Health, City of Coventry
}

The enemy air raid on Coventry on the night of November 14-15, 1940, was of great severity and the casualies were heavy. Damage to property in the city was widespread and included much injury to drainage, sewerage, and water communications. The social disturbance as affecting the lives and habits of the civil population was considerable, and, following the raid, evacuation-official and private-was on a large scale. This was due to the big number of damaged houses temporarily uninhabitable and to the hazard of further raids. In addition to the "complete" evacuees there was a larger number of those who continued to work in the city by day and to sleep elsewhere. The still commendably large residual adult population who "stuck it" in the city have had to take to shelter life to a greater extent than obtains in areas hitherto comparatively free from bombardment. All these things have brought momentous public health considerations in train, notably in the spheres of epidemiology, hospital policy, mental health, and housing. In these connexions the following brief notes may be of interest.

\section{Epidemiological}

In view of damage to drainage and water mains the typhoid hazard was obvious, and the preventive measures adopted included $(a)$ persistent local propaganda urging the boiling of drinking-water and milk; $(b)$ the chlorination of water supplies; (c) special injunctions to and supervision of makers and purveyors of foodstuffs in regard to cleanliness $;(d)$ all possible steps to secure the early restoration of water-pipes, sewers, and drains ; and (e) arrangements for large-scale anti-typhoid inoculation.

In regard to $(a)$, Press, posters, and Ministry of Information loud-speaker vans were used. The absence of gas supplies in many parts of the city added difficulty to the boiling of water and milk, but the public nevertheless took the matter seriously and resorted to open fires for boiling.

Immunization against Typhoid.-The view of the Ministry of Health in regard to mass immunization against organisms of the typhoid group is that there is no occasion for it unless conditions should arise which, in the opinion of the medical officer of health, render it necessary. The conditions which arose in Coventry following the big raid were exactly such as presumably were meant when the latter proviso was inserted.

Immediately after the raid three immunization clinics were opened at convenient points in the city-namely, at two hospitals and at a large central first-aid post. In addition one of the mobile first-aid units was commissioned temporarily as a mobile immunization clinic. These clinics were conducted by medical and nursing personnel of the public health department. Arrangements were made for the employees of large factories to be inoculated at the factories. The immunizing material was supplied free by the department, and the firms concerned contracted with private medical practitioners for the inoculation work. The campaign was well advertised by Press, posters, and loud-speaker vans. The immunizing material 